\title{
NOMBRES DE DIAS ENTRE LOS MAYAS PUTUNES
}

\author{
J. Eric S. Thompson *
}

Se conocen listas de días del calendario religioso, extinto o todavía en uso, en varios grupos mayas, en especial entre los yucatecos, tzeltales, tzotziles, chuhes, jacaltecas, ixiles, pokomchíes, quichés, cakchiqueles y tzutuhiles (ver la presentación tabular, Thompson, 1950: 58).

No ha subsistido una lista completa de los nombres de los veinte días de los maya putún o chontales de Tabasco y del sur de Campeche, pero las series pueden reconstruirse parcialmente partiendo de los nombres de días usados como apellidos por estos grupos y por los llamados lacandones de Dolores, de habla chol, en parte descendientes de los invasores putunes de la cuenca del río de La Pasión, y que se internaran más adentro de su territorio para escapar a la agresión española desde el Acalan oriental, como se discute más adelante.

El material de los putunes del sur de Campeche, o sea de la antigua provincia de Acalan, a la cual denominaremos Acalan occidental para distinguirla de la Acalan oriental, al sur del río de La Pasión, proviene de la matrícula de Tixchel de 1569 que, junto a materiales relacionados, es discutida con todo detalle en un brillante análisis de Scholes y Roys (1948, Apéndice C).

Luego de remover el material ajeno, tal como los prefijos masculinos y femeninos, y los nombres compuestos de los apellidos dobles, se reconocen los siguientes nombres de días mayas: Kanan o Canan; Mulu, Mulo o Molu; Lamat, Oc y Tzi.

El cacique de Canitzán, un cierto Andrés Cib, llevaba un nombre de día maya al final del siglo XVII (Villagutierre y Sotomayor, libro 6, cap. 4). Este pueblo, situado a orillas del río Usumacinta y no lejos de Tenosique, era muy probablemente de habla putún, como

\footnotetext{
* Traducción de Jean Pierre Laporte. Instituto de Investigaciones Antropológicas, UNAM.
} 
Tenosique y otros pueblos cercanos en esa época (Scholes y Roys, 1948: 25, 26, 445-446).

En relación a la Chontalpa, al oeste del delta de Usumacinta, Scholes y Roys (1948: 62) reportan solamente veinticuatro nombres propios mencionados en los registros disponibles para toda el área. Ninguno es definitivamente maya, pero once de ellos son nombres de días del calendario náhuat o náhuatl. Nombres similares de días ocurren también en Acalan y Potonchan, lo que se discute más adelante.

He anticipado la tesis de que los mayas que ocupaban el área al sur de Altar de Sacrificios al momento de la conquista española, eran un grupo mezclado que comprendía la población local manché-chol y descendientes de los maya putún quienes, subiendo el río Usumacinta, habían dominado Altar de Sacrificios y Seibal a finales del siglo VIII. Luego del colapso de estos centros al finalizar la época Clásica, la élite putún se retrae hacia el sur, fusionándose con la población local y estableciendo una nueva patria entre la Alta Verapaz y el río de La Pasión, a la que llamaron Acalan recordando su lugar de origen al sur de Campeche. En el siglo XVII se replegaron hacia el oeste luego de una derrota desastrosa a manos de los españoles llegados desde la Alta Verapaz, estableciéndose desde entonces en Dolores, en un recodo del río Lacantún, a una distancia aproximada de $100 \mathrm{Kms}$. al sur de Yaxchilán (Thompson, 1970, 1974).

Matrículas de Dolores y otras aldeas cercanas hechas poco después de la conquista de esta área en 1695 se encuentran en el Archivo General de Indias en Sevilla, de donde fueron copiadas por France V. Scholes (copias depositadas en el Museo Peabody, Universidad de Harvard), y muchos años después publicadas por Nicholas Hellmuth $(1969,1971)$.

Muchos de los apellidos de Dolores y sus aldeas muestran un rasgo poco usual en la forma de un prefijo que varía de $P a x$ o $P a z$ a $P a, P a p$ o $P a p a$. Estos prefijos han sido reportados hasta ahora solamente para otro grupo mayance, específicamente los putunes de Acalan occidental (p.e., Paxbolón, que dio su nombre a la relación). Esta es una fuerte confirmación de que los mayas de Acalan oriental eran, en parte, descendientes de los antiguos invasores putunes del río de La Pasión, provenientes del Acalan occidental. Es muy sugestivo que ambos territorios hayan llevado el nombre no maya de Acalan ("lugar de canoas" en náhuatl).

Las matrículas de Dolores y aldeas vecinas revelan otra liga im- 
portante con los putunes de Campeche y Tabasco: en cada área aparecen como apellidos nombres de días tanto del maya como del náhuat.

Los nombres de días mayas en las matrículas del área de Dolores son: Kanan o Canan, Tox, Mulu, Tzi, Lambat, Iq, Que, Eb, Ix, Men, Itznab y Chaoc. Los cuatro primeros, como hemos visto, se encuentran en la matrícula de Tixchel de Acalan occidental, así como Lamat, que corresponde al Lambat en Dolores; los demás nombres de días no aparecen en la matrícula de Tixchel. Una probable explicación de esta anomalía es que pocos nombres de residentes putunes de la desembocadura y estuarios del río Grijalva han subsistido, pero hay buenas razones para creer que putunes de esa región participaron en la ocupación del siglo VIII de la cuenca del río de La Pasión.

Quizá debiera agregarse a la lista de nombres el de Ahau, pues aparece como un elemento en nombres de jóvenes pero nunca asociado a nombres femeninos, por lo que es probable que sirviera solamente como un título.

Es dudoso que los nombres de los días en Dolores pertenecieran al elemento manché-chol de la población, puesto que ninguno de los apellidos manché-chol del sureste del Petén y del sur de Belice son nombres de días en los calendarios maya o náhuat que ocasionalmente se encuentran dispersos en los escritos de los padres Remesal y Ximénez. De esta manera, los nombres de los días maya y náhuat de la región de Dolores pueden ser atribuidos seguramente al elemento de descendencia putún en la población.

Los nombres de los días mayas de los tres grupos putunes están arreglados en el siguiente cuadro, en una secuencia normal, partiendo de Imix (columna 1). La columna 3 proporciona el equivalente más cercano en un calendario maya. Los calendarios en donde aparecen los nombres de los días se indican en la columna 4.

$\begin{array}{lll}2 \text { Iq } & \text { Ik } & \text { todos los calendarios mayas } \\ 4 \text { Kanan o } & \text { Khanan } & \text { tzeltal, tzotzil } \\ \text { Canan } & \text { Khana o Cana } & \text { chuh, jacalteca } \\ 6 \text { Tox } & \text { Tox } & \text { chuh, tzeltal, tzotzil, jacalteca } \\ 7 \text { Que } & \text { Ceh } & \text { chuh,quiché,cakchiquel, pokomchí } \\ 8 \text { Lamat o } & \text { Lamat } & \text { yucateco } \\ \text { Lambat } & \text { Lambat } & \text { chuh, saloma, tzeltal, tzotzil } \\ 9 \text { Mulu o } & \text { Mulu } & \text { chuh, tzeltal, tzotzil, jacalteca } \\ \text { Molu o Mulo Molo } & \text { chuh, tzeltal, tzotzil }\end{array}$




$\begin{array}{lll}10 \mathrm{Oc} & \text { Oc } & \text { yucateco } \\ 10 \mathrm{Tzi} & \text { Tzi o Tzii } & \begin{array}{l}\text { pokomchí, cakchiquel } \\ \text { quiché, cakchiquel }\end{array} \\ 12 \mathrm{~Eb} & \text { Tzih o Tz'i } & \text { yucateco } \\ & \text { Eu o Ehub } & \text { chuh } \\ 14 \mathrm{Ix} & \text { Ix o Hix } & \text { todos los calendarios mayas } \\ 15 \mathrm{Men} & \text { Men } & \text { yucateco } \\ 16 \mathrm{Cib} & \text { Cib } & \text { yucateco } \\ 18 \mathrm{Itznab} & \text { Etz'nab } & \text { yucateco } \\ 19 \text { Chaoc } & \text { Chauuc o } & \text { chuh } \\ & \text { Chauoc } & \end{array}$

Siete de los nombres mencionados - Kanan, Tux, Que, Lambai, Mulu, Eb y Chaoc - son los mismos, (o muy parecidos) que los nombres de los días en las listas chuh, tzeltal y tzotzil; seis de ellos -Lamat, Oc, Eb, Men, Cib e Itznab - se relacionan en forma similar a los nombres de los días del maya yucateco. $I x$ o Hix e $I k$ son comunes en todas las listas; $T z i$ corresponde al décimo día de las listas quiché, cakchiquel, zutuhil y pokomchí, así como la variante Tchii del ixil.

El compartir los nombres de los días con el maya yucateco por un lado y con el chuh, tzeltal, tzotzil y jacalteca por otro, está de acuerdo con la distribución geográfica de esas lenguas y dialectos. $\mathrm{Al}$ norte y al este de los putunes de Campeche y Tabasco se encontraba el yucateco y dialectos dependientes de éste (Cehach, Lago Pet'́n, Mopán, etc.) ; al sur de los putunes el palencano-chol, tzeltal, tzotzil y chuh (nada se sabe sobre el calendario palencano-chol).

El hecho de que los mayas putunes ocuparan una posición intermedia entre el yucateco y las lenguas mayances de Chiapas y Huehuetenango, tanto en la localización geográfica como en los nombres de días calendáricos, es indicio de una larga ocupación putún de este territorio y de la estabilidad de la población en dicha área en general.

Las variantes en los nombres de los días - Tzi y Oc; Lambat y Lamat - pueden ser explicadas por las dimensiones del territorio putún. Otro factor importante fue el aislamiento de varios siglos del grupo de Dolores de los putunes occidentales.

Se ha mencionado el uso de nombres de días náhuat como apellidos entre los putunes del golfo de Campeche, así como del área de

${ }^{1} \mathrm{La}$ poco usual terminación $e b$, salvo como instrumental, tiende a intercambiarse con eu, p.e., haleb, haleu; buleb, buleu. 
Dolores. El número y porcentaje de estos nombres de días en la primera zona decrece de acuerdo a la distancia desde los asentamientos de hablantes de náhuat; Acalan, según la evidencia actual, tiene el número menor de estos nombres, estando a mayor distancia de los asentamientos náhuat. Algo debe ser dicho sobre el término náhuat. Las diferencias más importantes entre náhuat y náhuatl son que el primero utiliza el fonema terminal $t$ en vez de $t l$, y tiende a usar un sonido de $u$ en donde el náhuatl usa $o$ (p.e. ucelut en náhuat; ocelotl en náhuatl).

Los nombres de los días en la matrícula de Acalan-Tixchel son del tipo náhuat; lo mismo sucede con las matrículas de la región de Dolores. Debido a que los portadores de estos nombres de días náhuat en Dolores eran descendientes muy probablemente de los colonizadores del valle de La Pasión de fines del siglo VIII, debemos concluir que la absorción putún de personas que llevaban nombres de días náhuat es resultado del contacto con gentes náhuat que residían en el delta del río Grijalva siglos antes de la entrada de grupos de Tula y Tenochtitlan.

Hubo seguramente asentamientos náhuat y náhuatl entre los putunes de la Chontalpa; su tamaño e importancia pudo acrecentarse con la expansión azteca. No puede determinarse hoy en día si los nombres de días en los apellidos de la Chontalpa son náhuatl o náhuat. Según las listas, la mayoría son náhuatl, pero es probable que debido a la influencia azteca, fuera nahuatlizado el nombre personal, o que el escribano lo hubiera hecho al estar acostumbrado al náhuatl. Creo firmemente que en aquel tiempo no se encontraban grupos en la Chontalpa que utilizaran nombres de días náhuatl como apellidos.

Presentamos los nombres de días náhuat y náhuatl para las divisiones de los putunes del golfo de Campeche y de Dolores, seguramente de aquellos refugiados de Acalan oriental.

ACALAN: Cipac o Tzipac (1); Ecate (2); Cali (3) y Caltzin, tal vez Calli y Tzin (3); Coate y Cua (5); Izcin e Izquintz (10); Malin (12); Acat (13); Zelut y Tzelut (14); Quiuit (19); Suchil (20) (Scholes y Roys, 1948, Apéndice C).

TEPETITAN: sabemos de solamente cuatro apellidos aborígenes de esta provincia que abarca el bajo Usumacinta y las tierras del delta al este de la Chontalpa. Uno es el nombre de día maya Cib, apellido del cacique de Canitzan, ya antes mencionado. Otro es Cipaque (Cipactl), nombre dinástico de los gobernantes de Potonchan (Scholes y Roys, 1948: $37 n$ ). En relación a los otros dos, En- 
rique Berlin nos dice que en el Archivo General de la Nación (México, D. F.), encontró un texto mutilado de 1588 en mexicano (Civil 682). Los diversos testigos tenían apellidos españoles salvo dos excepciones: Pedro Cecbati y Juan Celot. Berlín, en 1952, reconstruye el primero como Cipactli (no hay $b$ en náhuatl) y el segundo como Ocelotl. En vista de la fuerte influencia náhuat en la región, pueden ser corregidos a Cipact y Ocelot.

CHONTALPA: Zipaque (1); Coatle (5); Mazat y Mazatle (7); Tuxtl y Tustle (8); Izquin (10); Malyna (12); Acatel y Hacatl (13); Uzelotl, Ozelote y Uzelo (14); Olin (17); Tequepal (18); Suchil (20) (Sholes y Roys, 1948: 62).

DOLORES (ex-Acalan oriental) : Cali (3); Cuat (5); Maza (7): Zelu y Zelut (14); Hulin (17); Quiauit (19); Xuchit (20). Izkin puede ser una variante de Izcuint (10) (Hellmuth, 1969, 1971).

De ser correcta mi tesis sobre la invasión putún del valle de La Pasión a finales del siglo VIII (observar los glifos Cipact sobre los gobernantes de Seibal en la estela 3), la aparición de nombres náhuat entre los putunes antecede al documento colonial mencionado por cerca de un milenio, tiempo suficiente para que los nombres de un calendario ajeno a sus usuarios, sufra fuertes distorsiones. Asimismo, sugiero que para el siglo XVI, los nombres calendáricos tanto maya como náhuat en el golfo de Campeche y en Dolores, eran heredados y no asignados según el día del nacimiento.

Hay muy pocos casos de nombres de día con numeral. Una explicación a esto puede encontrarse en una observación de Carrasco (1964: 324) que dice que en el Popol Vuh y en los Anales de los Cakchiqueles, sólo los gobernantes llevaban tanto nombre de día como numeral.

\section{BIBLIOGRAFIA}

Carrasco, P.

1964 Los nombres de persona en la Guatemala antigua. Estudios de Cultura Maya, 4: 323-34, México.

Hellmuth, N. M.

1969 Seventeenth Century Chol Maya of Peta and Map, Chiapas, American Society for Ethnohistory, 17th Annual Meeting, Ithaca, N. Y., Mimeographed.

1971. Matrícula de Dolores, San Ramon Map and San Antonio Pecta, Material copied from legajos in Archivo General de Indias, Sevilla. Mimeographed. 
Scholes, F. V. and R. L. Roys

1948 The Maya Chontal Indians of Acalan-Tixchel, a contribution to the history and ethnography of the Yucatan peninsula. Carnegie Institution of Washington, Pub. 560, Washington.

Scholes, F. V. and J. E. S. Thompson

1975 The Francisco Pérez probanza of 1654-56 and the Matrícula of Tipu, Belize. Hopefully to be published in volume on Maya of Quintana Roo and Belize, Grant Jones, editor.

Thompson, J. E. S.

1950 Maya hieroglyphic writing: and introduction. Carnegie Institution of Washington, Pub. 589, Washington, Norman, 1960.

1970 Maya history and religion. University of Oklahoma Press, Norman.

1974 "Los putunes en la cuenca de la Pasión al término de la época clásica". Proceedings XLI International Congress of Americanists, México. In press.

1975 A proposal for constituting a Maya sub-group, cultural and linguistic, in the Peten and adjacent regions. Hopefully to be published in volume on Maya of Quintana Roo and Belice, Grant Jones, editor.

Villagutierre y Sotomayor, J. DE

1963 Historia de la conquista de la provincia de el Itzá, reducción y progresos de la de el Lacandón. Biblioteca Goathemala, Vol. 9, Guatemala. 